\title{
The Development And Validation Of An End-User Satisfaction Measure In A Student Laptop Environment
}

\author{
Sung Kim, Minnesota State University, Mankato, USA \\ Juan (Gloria) Meng, Minnesota State University, Mankato, USA \\ Jon Kalinowski, Minnesota State University, Mankato, USA \\ Dooyoung Shin, Minnesota State University, Mankato, USA
}

\begin{abstract}
The purpose of this paper is to present the development and validation of a measurement model for student user satisfaction in a laptop environment. Using a "quasi Delphi" method in addition to contributions from prior research we used EFA and CFA (LISREL) to identify a five factor (14 item) measurement model that best fit the data. The structural model identified two factors related to overall student satisfaction. Suggestions and implications for how to use this measure are provided.
\end{abstract}

Keywords: End-Users Satisfaction; Laptop Initiative; Confirmatory Factor Analysis; Instrument Development

\section{INTRODUCTION}

Cnformation Technology (IT) has become an integral component of learning environments in higher education. The most recent developments in IT have brought about fundamental changes in the ways that the university creates and disseminates ideas, knowledge, and understanding. Technology can significantly enhance student learning, transform the content of courses, alter learning-related practices, change classroom dynamics, and affect the relationship between students and faculty. Consequently, IT has become pervasive in higher education and the incorporation of IT into classrooms has not only added value to student learning but also become a necessity for students to adapt to a growing technological environment.

In an effort to keep abreast with the current trend in higher education, and to meet the needs of students and employers who are actively looking for technologically agile students, a laptop initiative was launched in a College of Business at a Midwest University. The College of Business (COB) is AACSB accredited and consequently mission driven with a need to provide support to keep the college on track to achieve broadly stated purposes. The college's mission statement clearly points out that the college should provide a "focus on educating students in a technologically-advanced, active learning environment" (Kim et al., 2005). In order to operationalize a technologically-advanced, active learning environment, the college executed the initiative that included substantial renovations and investment in the infrastructure (i.e., Smartboards, student seating pods, wireless technology, centrally located printer access, support services for leased/purchased laptops etc.).

The laptop initiative allowed students to access technology and the Internet anywhere on campus. The portability of a laptop also enables more convenient computer access for both students and faculty, and when coupled with classrooms set-up for connectivity, enhance on-site learning, and classroom experiences (Driver, 2002). The Learning Technology Report (1999) suggests numerous reasons why universities and colleges are requiring laptop computers for their students. Frequently mentioned reasons include: the long-term solution to problems associated with computer labs, a way to differentiate yourself from the competition, the empowering of students and a way to increase computer skills, enhanced student marketability and improved student retention rates, the standardization of hardware and software, and the new imperatives of a knowledge economy. The benefits, drawbacks, and prerequisites of a laptop initiative have been well documented in Bovinet and Bovinet (2003), Brunswick and Zinser (2003), Crouch (2001), McVay et al. (2005), Kontos (2004), Poindexter et al. (2001) and Sanford (2000). The impact of a laptop initiative on teaching and student learning is not a straightforward or institution-specific matter and should be evaluated on a long-term and continuing basis. However, better communication and collaboration between faculty, students, and staff 
have been mentioned as the key benefits for the university. Additionally, based on the substantial investment of both human and financial resources the satisfaction of users or students is a major concern. This paper has 3 broad objectives which include: (1) the development of a measure for student satisfaction for a technological initiative (specific application) within an educational or unique setting, (2) the use of items using Likert-type scales which provide a better alternative to semantic differential scaling, and (3) to provide psychometric support for the reliability and validity of the components and items generated.

\section{ASSESSING THE LAPTOP INITIATIVE}

The increased usage of laptops and computers in education has resulted in a plethora of studies reflecting the impact of this intervention on learning. Unfortunately, the always pressing issue of whether measures provide us with the appropriate information to develop meaningful insight into the effects of these interventions persists. While efforts to gather feedback regarding customer satisfaction, user satisfaction or student satisfaction are to be applauded, efforts to determine what should be measured from the users' perspective is the most important element in this process. In order to provide a high quality 'laptop initiative' and assess the effectiveness of the program, most higher education institutions conduct some form of student satisfaction survey. As a part of a continuous improvement strategy, universities typically measure student satisfaction by focusing on such items as training and orientation support, technical support for hardware and software, the enhancement of learning, and economic issues. Student satisfaction surveys with a laptop initiative can be a rich source of information for continuous program improvements, but only if they are examined carefully and used within a consistent framework. Through these surveys, universities can identify the answers to such questions as (1) what aspects of the initiative do students care about the most?, (2) what aspects of the initiative do students find the most and least satisfying?, (3) how can the initiative best meet student expectations?, (4) how and where can the university's limited resources be allocated to effectively improve students' overall satisfaction? Suffice it to say that the main goal of these surveys is to clearly identify key determinants of students' overall satisfaction and provide institutional decision makers with the information necessary to prudently organize improvement efforts and set priorities. Such satisfaction surveys enable institutions to pinpoint the laptop initiative's strength and weaknesses (i.e., areas in need of improvement).

The Management Information Systems (MIS) literature has developed a strong stream of research on the satisfaction of end users and the development of an end user computing construct (EUC) (Rainer \& Harrison, 1994; Mahmood, Burn, Gemoets, \& Jacquez, 2000; Chen, Soliman, En Mao, \& Frolich, 2000; Doll \& Torkzadeh, 1988; Somers, Nelson, \& Karimi, 2003; Abdinnour-Helm, Chaparro, \& Farmer, 2005). Our purpose is to highlight key areas from this literature in the development of an end user instrument for students in an academic setting. Additionally, student satisfaction has a long history in higher education. Focusing on student satisfaction allows universities to adapt to student needs based on a clear understanding of student expectations (Elliott \& Shin, 2002). Certainly, the user satisfaction and student satisfaction literatures provide important direction for development of satisfaction instruments in the academic setting where technology initiatives are prevalent. In typical user satisfaction surveys, survey instruments are often designed from the organization's perspective. In such surveys, administrative and technical staffs are so focused on technology, economic, and administration issues that they frequently fail to address major concerns of users critical to improving user satisfaction. Also, these surveys may not be linked to internal metrics that drive service changes, and may not be able to generate information that produce the desired effects on the improvement of service. In order to better understand the true needs of students, who are the end-users of the Laptop University, we carefully focus on the instrument development process from a student's perspective rather than from the faculty or administrative staff perspective. While efforts to gather feedback regarding customer satisfaction, user satisfaction, or student satisfaction are to be applauded, it is our opinion that efforts to determine what should be measured from the users perspective is the most important element in this process. Accordingly, we provide a process using some modifications to the Delphi Method for gathering inputs from experts on what to measure. We suggest students are the experts on how they experience a laptop initiative. We have also chosen to simply refer to these modifications as a "quasi-Delphi" method for instrument development.

The objective of item creation in a measure is to ensure content validity. Content validity is the representativeness or sampling adequacy of the construct domain (Campbell, 1976; Carmines \& Zeller, 1979; Kerlinger, 1973). In determining the content of items for the satisfaction of the laptop initiative we used a quasi-Delphi process in conjunction with contributions developed through research on user and student satisfaction.

The Delphi method of inquiry is based on a structured process of collecting and distilling information or knowledge from a group of experts by means of a series of questionnaires interspersed with controlled opinion 
feedback (Ziglio, 1996). Wilhelm (2001) has provided a review of the history and use of the Delphi technique in numerous applications to the social sciences and physical sciences. For example, in the area of education theory the Delphi process was used to determine important workplace skills and competencies that businesses desire in employees (Dean \& West, 1999; Harris, 1996; Wilhelm, 1999). The Delphi technique has also been used in a variety of other situations (i.e. forecasting, policy development, assessment of critical thinking skills) for the gathering of objective and subjective data. However, the Delphi process is characterized primarily by its particular structure for gathering and processing information rather than any particular analytical process, evaluative model, or epistemological foundation. In this paper we first outline the process used to develop our instrument. Second, we use EFA and CFA with recommendations for future instrument development.

\section{USER SATISFACTION}

User satisfaction has been suggested to be one of the key factors leading to the success of information systems (Schiffman, Meile, \& Igbaria, 1992; Szajina \& Scamell, 1993; Ditsa \& MacGregor, 1995; Gelderman, 1998; Al-Khaldi $\&$ Wallace, 1999). However, results from end-user satisfaction studies tend to show highly variable results with some studies giving support to the influence of one factor such as user attitudes while others find little or no support for the same variable (Mahmood, Burn, Gemoets, \& Jacquez, 2000). Consequently, Mahmood et al. (2000) performed a meta analysis (1986-1998 period) on the support of key indicators (factors) for three major categories previously identified in the literature as affecting information technology (IT) user satisfaction. These categories included user perceived benefits, user-related individual characteristics, and organizational support or readiness to use IT. Most relevant to this research, was the conclusion that the key variables (factors) related to user satisfaction included user involvement in system development, perceived usefulness of the IT system, user experience, organizational support, and user attitude toward the information system. Specifically, these results are important to our study not only due to the focus on student satisfaction of an IT initiative within a College of Business, but also because of the implication for the items in a measure that give timely information and insight into how we need to adapt to student satisfaction feedback. Based on the effect sizes resulting in the above identified key factors, it was clear that a major determinant for user satisfaction is greater user involvement in system development which "in turn is likely to lead to the design of systems which are perceived to be useful and hence viewed more positively by users with enhanced experience. This will influence expectations and skills and should lead to the development of systems which are easier to use" (Mahmmod et al., 2000, p. 767).

Notably, the effect size of user expectations was not found to be as important as the other variables mentioned above. We note this result due to the heavy theoretical emphasis (expectation continuance theory, ECT) placed on the importance of expectations in the consumer behavior literature (consumer satisfaction) and its relevance for user satisfaction in the IT setting (Bhattacherjee, 2001; Oliver, 1980). We also note other literature contributions to the user satisfaction construct which include job satisfaction (Locke, 1976), quality management (Parasuraman, Zeithaml, \& Berry, 1988), as well as library information sciences and student satisfaction in academic settings (Browne, Kaldenberg, Browne, \& Brown, 1998; Elliott \& Shin, 2002). Many of these literatures have included notions from psychology and social psychology on the relationship between expectations, confirmed expectations, intentions, behavior, and satisfaction (Ajzen \& Fishbein, 1977; Bem, 1972; Locke, 1976; Oliver, 1993; Vroom, 1964). Our purpose is not to isolate or review all the contributions to the notion of user satisfaction, but to acknowledge the research history and point out a critical observation from recent investigations of satisfaction in general. That is, whether one is looking at job satisfaction, user satisfaction, consumer satisfaction, student satisfaction, or library user satisfaction, each situation will have different determinants of satisfaction which provides clear evidence for varying and conflicting conceptualizations of the satisfaction concept (Yi, 1990). For example, in the library and information science field, Applegate (1993) has concluded that more research is needed to determine the factors or service that contribute to user satisfaction at both the micro (individual) and macro (organizational) levels. This observation was made because most generic user satisfaction questionnaires such as SERVQUAL (Parasuraman, Zeithaml, \& Berry, 1988) do not provide sufficient information for libraries to make the necessary changes in their service delivery. The relevance of this conclusion lends credence to the necessity of developing measures of satisfaction based on perceptions of what users deem to be key criteria for their specific situation. Consequently, we develop our user satisfaction measure based on input from student users of an IT initiative in a College of Business. We also will draw upon the conclusions from prior research to assist us in the organization of student input on satisfaction criteria as well as initial queuing questions for initial input. The next part of this paper will describe the iterative process used to gather student input on their satisfaction of the IT initiative. 


\section{IDENTIFYING CRITICAL DETERMINANTS OF END-USERS' OVERALL SATISFACTION}

The development of the instrument involved four phases. These phases included the development and administration of an initial open ended instrument to gather student input on criteria they thought critical to the satisfaction of users in the College of Business laptop initiative. These open ended questions were prompted by prior research on IT systems where certain broad categories have been identified as critical to IT user satisfaction. Phase two involved collating and recording this initial input so it could be organized into meaningful categories. Phase three involved the development of the instrument in order to gather each student's input on the importance of a particular item as well as their perception of how well that particular item was perceived to have been satisfied. Phase three also included the administration of the instrument to a cross-sectional sample of 237 students participating in the laptop initiative. Phase four involved analyzing data using exploratory and confirmatory factor analysis.

As stated, phase one included the administration of an open ended instrument where 3 very broad questions were used as an initial stimulus to gather student input. Students were asked to identify three to five criteria in the areas of support, individual needs, and attributes of the technology. This is consistent with the broad categories of individual perceptions of benefits and convenience as well as various organizational types of support identified in previous research. We also gathered data in the final instrument on user characteristics, another key broad category related to user satisfaction. The broad category of technology was simply used to generate criteria associated with any elements of concern to students with the technology initiative. In retrospect, after looking at student responses to these open ended questions, we found items that overlapped across all three areas. Students appeared to state their most important concerns regardless of the area or category with which they were prompted. This resulted in phase two taking on new meaning with respect to placing items within meaningful categories for the development of the final instrument in phase three. This initial instrument was administered to 56 students.

Phase two of the process involved the recording and collating of initial student input. This process entailed an evaluation of each response and the placement of items into groups that appeared to address similar concerns. Based on this process, we were able to identify seven broad categories which included training, orientation, helpdesk/tutors/tutorials/helpline, technical support, technology issues (software, printers, wireless access, upgradeability etc.), computer purchase/lease/economic issues, and use of laptop in class/enhancement of learning. After further review of items within these broad categories we developed the following final categories for questions: training and orientation support provided to adopters, end user support, technology, economic issues, and enhancement of learning/use of laptops in classrooms. It is clear from the final categories that there will be certain issues that cannot be evaluated from simple modification of standard satisfaction instruments. For example, it was clear that students were concerned about the cost of laptops and whether they had sufficient input into whether they had the option to lease or buy laptops. This clearly supports our position that items for evaluation of user satisfaction needs to come from the so-called experts/users as well as the use of prior empirical support for satisfaction determinants.

Phase three of the instrument development included adding a section to assess user characteristics or demographic information. We also included a response for the overall satisfaction with the laptop initiative. Finally, we structured each question's response format as a Likert Scale which allowed us to evaluate not only the importance of each item, but the students overall level of satisfaction with each item. The questionnaire of 55 items is provided in Appendix 1 with the starred items reflecting those items that loaded on one of the six components obtained through PCA.

\section{METHODOLOGY}

\subsection{Questionnaire Design}

In typical user satisfaction surveys, survey instruments are often designed from the organization's perspective. In such surveys, administrative and technical staffs are so focused on technology, economic, and administrative issues that they frequently fail to address true concerns of users that are critical to improving user satisfaction. With the purpose of better understanding the true needs of students, who are the end-users of the laptop initiative, we carefully designed the questionnaire from the students' perspective rather than from the faculty or administrative staff perspective. The survey instrument was developed through a three-phase iterative process (Kim et al., 2005) based on student comments and suggestions. 
A 61-item survey questionnaire (55 satisfaction) items with 4 demographic questions and 2 more questions measuring (1) overall satisfaction and (2) whether the student would recommend the initiative to others based on their experience) was constructed to explore five themes in the areas of: (A) training and orientation support provided to adopters, (B) end user support, (C) technology, (D) economic issues, and (E) the enhancement of learning and use of laptops in classrooms. Students were asked to rate their expectations and experiences with the laptop initiative with regard to "importance" and "satisfaction." The items were Likert-type statements on a five-point scale ranging from (1) Strongly Disagree to (5) Strongly Agree (See Appendix 1).

\subsection{Sample and Sampling Adequacy}

A convenience sample of 237 sophomore, junior, and senior students from the College of Business was collected. Table 1 summarizes key demographic characteristics of students used in the survey. As shown in Table 1, approximately $90 \%$ of the students were juniors and seniors, which is the result of the college's admission policy where students are admitted to the college after they complete the basic requirements in their freshmen and sophomore years. Table 1 also shows that sampled students have an average of 2.3 years of experience with the laptop and wireless technology, along with fairly strong computer skills.

Table 1: Demographic Profile of Sample

\begin{tabular}{|l|c|}
\hline \multicolumn{1}{|c|}{ School Year } & \\
\hline \multicolumn{1}{|c|}{ Major } & $8.9 \%$ \\
\hline Sophomore & $28.3 \%$ \\
\hline Junior & $62.8 \%$ \\
\hline Senior & $15.7 \%$ \\
\hline \multicolumn{1}{|c|}{ - 237) } \\
\hline Accounting & $16.1 \%$ \\
\hline Finance & $31.3 \%$ \\
\hline General Management & $7.4 \%$ \\
\hline Human Resource Management & $2.6 \%$ \\
\hline International Business & $20.4 \%$ \\
\hline Marketing & $3.9 \%$ \\
\hline MIS & $2.6 \%$ \\
\hline Other & Mean 2.28 years \\
\hline & Mean 2.26 years \\
\hline Number of Years Experience with the Laptop & Mean 3.84 rating \\
\hline Number of Years Experience with Wireless Technology & \\
\hline $\begin{array}{l}\text { Self-Reported Computer Skills } \\
\text { (5 being Very Strong, 1 being Very Weak) }\end{array}$ & \\
\hline
\end{tabular}

To determine whether the data set is likely to be a candidate for factor analysis both the Bartlett test of sphericity and the Kaiser-Meyer-Olkin (KM0) measure of sampling adequacy was examined. The KMO measure was .876 and is considered meritorious in terms of suggesting the data set include variables that are linearly related. The KMO measure is based upon the correlation and partial correlation where the numerator of the measure is the sum of squared correlations of all variables and the denominator is this same sum plus the sum of squared partial correlations of each variable $i$ with each variable $j$ controlling for others in the analysis. The Barlett test of sphericity had a chi-square value of 6037.5 (sig. at .0000) and suggests that the data are from a multivariate normal distribution where the variables have correlations significantly different from 0 . Both tests suggest that the intercorrelation matrix contain enough common variance to make factor analysis worth pursuing.

There does not appear to be a scientific answer to the question of how many cases are necessary to perform a factor analysis. Several of the arbitrary "rules of thumb" include the rule of 10 or there should be at least 10 cases for each item in the instrument being used. Alternatively, the STV (subject to variable) ratio should be no lower than 5 or the Rule of 100 states that the number of subjects should be the larger of 5 times the number of variables, or 100 . Clearly we are just short of the last rule $(5 \times 55=275)$ with a ratio of 4.31 . We would therefore suggest our sample size is somewhere around fair to good with this sample size meeting less restrictive guidelines such as the Rule of 150 where Hutcheson and Sofoniou (1999) recommend at least 150-300 cases. 


\subsection{Data Analysis}

We conducted an exploratory factor analysis with varimax rotation using SPSS. We modified the instrument and identified five factors composed of 14 items $(\mathrm{N}=118)$ (Kerlinger, 1978; Schoenfeldt, 1984). Without specifying the number of factors, 14 factors emerged with eigen values greater than 1 and an examination of the scree plot indicated further factors after 5 did not add more than $2.5 \%$ to variance explanation. Loading cutoffs appear to be somewhat arbitrary. Common social science practice suggests a minimum cut-off of .3 or .35 while Norman \& Streiner (1994) provide the formula when $\mathrm{N}$ is 100 or more of Min Factor Loading $=5.152 /[. S Q R T(\mathrm{~N}-2]$. Another arbitrary rule of thumb terms loading as "weak" if less than .4, "strong" if more than .6, and otherwise as "moderate." We chose to use .5 as loading because it appears to provide simplicity in the number of variables (items) per factor and would be in a moderate range. After examining the items for the 5 factors, we interpreted the factors to be relevant use (factor 1), training (factor 2), technical support (factor 3), facility support (factor 4), and choice in the type and specifications of laptops (factor 5). We used the factor analyses to specify the measurement model which was then confirmed using Lisrel 8.80 on the second half of the sample and tested the structural model on two overall satisfaction measures using the total sample.

\subsubsection{Reliability}

Figure 1 provides the measurement and structural model with the measurement model reflected by the indicators (items) for each of the 5 factors (latent constructs). We hypothesized a 5 factor model to be confirmed in the measurement portion of the model. The 14 item instrument had a reliability of .93 (Cronbach's Alpha). The reliability of each factor was: factor 1 (relevant use $)=.807$; factor 2 (training $)=.780$; factor 3 (technical support $)=.709$; factor 4 (facility support $)=$ .614 ; and factor 5 (choice) $=.647$. Table 2 provides the factor loadings and reliability coefficients. These data support the further consideration of whether the constructs are valid.

\subsubsection{Validity}

A CFA on fourteen items (5 latent constructs) were analyzed using SEM. All scale items were loaded on their indicated latent construct with all loadings above .60 with the exception of one item reflecting facility support at .57 . The goodness of fit indices used to assess the validity of the measurement model included the Chi-square/df ratio, RMSEA, NGI, CFI, and NNFI. The CFI and NNFI both exceeded .95 reflecting a close fit. The NFI at .91 would be considered good model fit. An RMSEA of .05 to .08 reflects close fit (Schumacker \& Lomax, 2010) and Chi-square/df ratio of 1.26 also reflects close fit. These values indicate a good fit between the model and the observed data. The model fit statistics from the SEM measurement model analysis are reported in Table 2 and the measurement model is again reflected in Figure 1 with the structural model. A correlation table is shown in Appendix 2. 


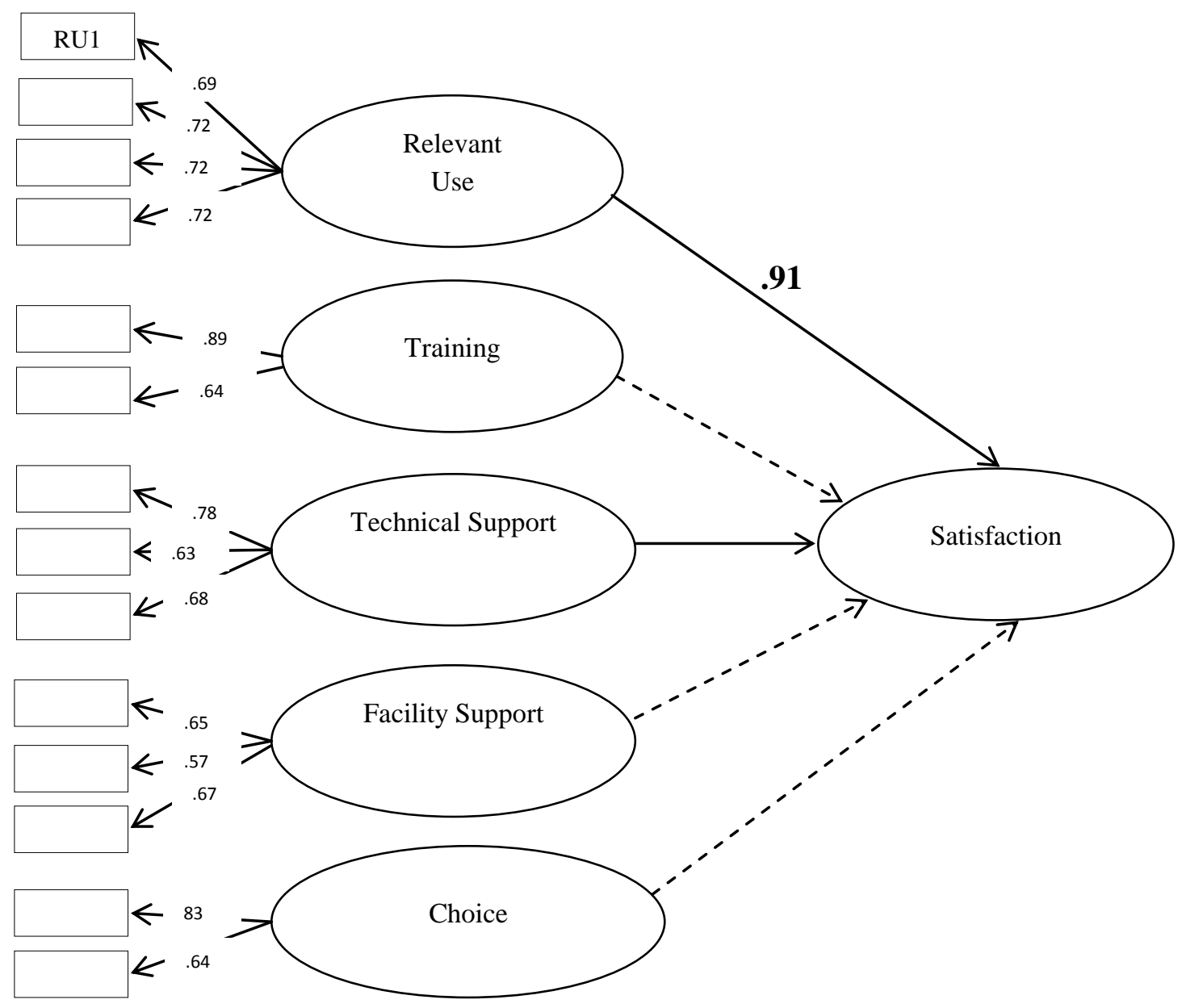

Figure 1: Measurement and Structural Model

Table 2: Reliability and Validity

\begin{tabular}{|c|c|c|c|c|c|c|c|}
\hline \multirow[t]{2}{*}{ Construct } & \multirow[t]{2}{*}{ Item } & \multicolumn{5}{|c|}{ Loadings } & \multirow[t]{2}{*}{ Corrected Item-Total Correlations } \\
\hline & & RU & $\mathbf{T}$ & TS & FS & $\mathbf{C}$ & \\
\hline \multirow{4}{*}{ Relevant Use } & ES2 & .69 & & & & & .634 \\
\hline & ES16 & .72 & & & & & .562 \\
\hline & ES3 & .72 & & & & & .653 \\
\hline & ES8 & .72 & & & & & .652 \\
\hline \multirow{2}{*}{ Training } & AS9 & & .89 & & & & .640 \\
\hline & AS10 & & .64 & & & & .640 \\
\hline \multirow{3}{*}{ Technical Support } & $\mathrm{CS} 2$ & & & .78 & & & .600 \\
\hline & BS4 & & & .63 & & & .505 \\
\hline & BS2 & & & .68 & & & .484 \\
\hline \multirow{3}{*}{ Facility Support } & BS6 & & & & .65 & & .430 \\
\hline & $\mathrm{CS} 3$ & & & & .57 & & .427 \\
\hline & CS4 & & & & .67 & & .430 \\
\hline \multirow{2}{*}{ Choice } & DS6 & & & & & .83 & .482 \\
\hline & ES13 & & & & & .64 & .482 \\
\hline Cronbach's Alpha & & .807 & .780 & .709 & .614 & .647 & \\
\hline
\end{tabular}




\subsubsection{Structural Model}

The structural model reflected in Figure 1 included two overall indicators of satisfaction. The first item was "My overall satisfaction with the laptop initiative is" (very dissatisfied to very satisfied on a five point scale) and the second item was "I would recommend the laptop initiative to other students" (strongly disagree to strongly agree on a five point scale). Two of the five latent variables relevant use (standardized path coefficient $=.91$ ) and technical support (standardized path coefficient $=.25$ ) were significantly related to overall satisfaction and the fit indices support the conclusion of a close or strong fit. The model fit statistics are reflected in the bottom half of Table 3 where the NFI (.94), CFI (.97), and NNFI (.96) all exceeded .90 indicating good to close fit. The RMSEA of .06 indicates strong fit and the Chi square/df ratio of 2.03 is $\leq 2$ or 3 (Schreiber J.B. et al., 2006) or between 2 and 5 (Marsh \& Hocevar, 1985). Clearly, of the two latent variables that were significant it appears that relevant use is more important to overall satisfaction than is technical support.

Table 3: SEM Fit (Measurement Model \& Structural Model)

\begin{tabular}{|l|c|c|c|c|c|c|c|c|c|}
\hline & $\mathbf{N}$ & $\mathbf{C h i}^{\mathbf{2}}$ & $\mathbf{d f}$ & $\mathbf{S i g .}$ & $\mathbf{C h i}^{\mathbf{2}}$ /df & RMSEA & NFI & CFI & NNFI \\
\hline Measurement Model & 118 & 84.49 & 67 & .000 & 1.26 & .05 & .91 & .98 & .97 \\
\hline Structural Model & 237 & 180.93 & 89 & .000 & 2.03 & .06 & .94 & .97 & .96 \\
\hline
\end{tabular}

\section{RESULTS AND DISCUSSION}

In this section we will discuss the contribution of this research to the overall understanding of the measurement of user satisfaction. Next, we will suggest how the developed instrument might be applied. Finally, we consider the limitations of this study and make suggestions for future research.

The purpose of this study was to determine what variables of a laptop initiative were important to the satisfaction of student users within an educational setting. We reviewed the literature to identify variables previously identified as being most important to end-user satisfaction and based on prior findings developed a questionnaire that emphasized the perceptual items students deemed as important to their overall satisfaction. While Doll and Torkzadeh (1988) have encouraged the MIS research community to move towards a standard end-user satisfaction measure, measurement theory suggests that a single measure across different individuals in varied settings may not be achievable. We developed a measure in this circumstance due to the importance of our users (students) as well as wanting to gain insight into what aspects of the laptop initiative needed changing. This initiative involved extensive commitment from faculty, students, and administration. Accordingly, we were most concerned with the content of items that would best inform decision making on a continual basis as we implemented the initiative with more students over time as well as measures based upon theory and prior research. Prior research has indicated up to 9 variables as influencing information technology satisfaction (Mahmood, Burn, Gemoets, \& Jacquez, 2000). The most important of these included user involvement, perceived usefulness, user experience, organizational support, and user attitude. Our research has provided strong support for two of these latent variables in an educational setting. Specifically, our latent variable which had the strongest relationship with overall satisfaction (standardized $r=.91$ ) would appear to be consistent with "perceived usefulness." Additionally, indicators of technical support which included readily or timely available support, prompt response and easy access to a help desk appear to be consistent with "organizational forms of support." Finally, while prior research (Mahmood, Burn, Gemoets, \& Jacquez, 2000) has emphasized the role that "user involvement" has in IT satisfaction, our findings suggest that student involvement in "choices" regarding the specification of a laptop, type of machine, along with the economics of the purchase/lease decision may not be that important. Additionally, while organizational support in terms of "technical support" was supported as important to overall satisfaction in this research, other forms of support such as "training" and "facility support" (indicated by PC setup, access to internet/wireless, and work station availability) were not shown to be related to overall satisfaction.

We recommend that researchers considering the importance of user satisfaction in an educational setting and focusing on students consider the specific items reflecting how technology is used in learning. This research suggests that "perceived usefulness" involved items which reflect how the laptop is designed for usage in a course and that the use is clearly connected to the enhancement of student learning along with support communication with the instructor. Items that have been identified with the role of organizational support include concerns of a prompt and readily available response to problems and the insuring that support is located in close proximity. 
Reliable and valid measures are considered to be the sine qua non for the advancement of knowledge in any discipline. Many scholars repeat and bemoan the need to spend more time providing measures that have been operationalized consistent with theory and subjected to the rigors of proper measurement methods. Most important to these concerns is the continuous effort to provide insight to theoretical constructs through use of measures for different populations and settings. This research is a response to those concerns. Limitations of this study include the confidence we have that the latent variables confirmed will generalize across time settings and different populations so replication is necessary. The research method used in this study may also result in common method bias (due to self-report) but as Meade et al. (2007) have noted, in many cases, common method bias or variance may be trivially small and certainly does not necessarily jeopardize the validity of study conclusions.

\section{AUTHOR INFORMATION}

Dr. Juan Meng earned her Ph.D. in 1991. She is currently an associate professor of marketing at Minnesota State University, Mankato. E-mail: juan.meng@mnsu.edu

Dr. Dooyoung Shin earned his Ph.D. at the University of Iowa, Iowa City in 1987. He is currently a professor of production and operations management at Minnesota State University, Mankato. His teaching and research interests include POM, quality management and management science.

Dr. Jon Kalinowski earned his Ph.D. at the University of Iowa, Iowa City in 1987. He is currently a professor of strategic management at Minnesota State University, Mankato. His teaching and research interests include strategic management, cross cultural differences in role conflict-ambiguity, life satisfaction and organizational commitment, and student/end-user satisfaction. E-mail: jon.kalinowski@mnsu.edu (Corresponding author)

Dr. Sung Kim earned his Ph.D. at the University of Nebraska, Lincoln in 1995. He is currently a professor of management information systems at Minnesota State University, Mankato. His teaching and research interests include MIS, decision support systems and end-user satisfaction.

\section{REFERENCES}

1. Abdinnour-Helm, S., Chaparro, B., \& Farmer, S. (2005). Using the end-user computing satisfaction (EUCS) instrument to measure satisfaction with a web-site. Decision Sciences, 36(2), 341-365.

2. Aladwani, A. (2002). Organizational actions, computer attitudes, and end-user satisfaction in public organizations: An empirical study. Journal of End-User Computing, 14(1), 42-50.

3. Ajzen, I., \& Fishbein, M. (1977). Attitude-behavior relations: A theoretical analysis and review of empirical research. Psychological Bulletin, 84, 888-918.

4. Al-Khaldi, M. A., \& Wallace, R. S. (1999). The influence of attitudes on personal computer utilization among knowledge workers: The case of Saudi Arabia. Communications of the ACM, 29(31), 185-204.

5. Bem, D. J. (1972). Self-perception theory. In L. Berkowitz (ed.), Advances in experimental social psychology (6, pp. 1-62). New York: Academic Press.

6. Bhattacherjee, A. (2001). Understanding information systems continuance: an expectation-confirmation model. MIS Quarterly, 25(3), 51-370.

7. Bovinet, J. W., \& Bovinet, J. A. (2003). Laptop University: The effect on enrollment and retention. Proceedings of the Academy of Educational Leadership, 8(2), 3-9.

8. Browne, B. A., Kaldenberg, D. O., Browne, W. B., \& Brow, D. (1998). Students as customers: Factors affecting satisfaction and assessments of institutional quality. Journal of Marketing for Higher Education, 8(3), 1-14.

9. Brunswick, G. J., \& Zinser, B. (2003). Mandatory computer initiatives and their impact upon marketing strategy for Colleges and Universities. Academy of Educational Leadership Journal, 7(3), 65-73.

10. Chen, L., Loliman, D. S., Mao, E., \& Frolick, M. (2000). Measuring user satisfaction with data warehouse: An exploratory study. Information \& Management, 37, 103-110.

11. Crouch, R. N. (2001). Making ubiquitous computing work. College Planning and Management, December, 17-18.

12. Doll, W. J., \& Torkzadeh, G. (1988). The measurement of end-user computing satisfaction. Management Information System Quarterly, 12(2), 259-274. 
13. Driver, M. (2002). Exploring student perceptions of group interaction and class satisfaction in the web-enhanced classroom. The Internet and Higher Education, 5, 35-45.

14. Elliott, K. M., \& Shin, D. (2002). Student satisfaction: An alternative approach to assessing this important concept. Journal of Higher Education Policy and Management, 24(2), 197-209.

15. Hutcheson, G., \& Sofroniou, N. (1999). The multivariate social scientist: Introductory statistics using generalized linear models. Thousand Oaks, CK: Sage Publications.

16. Kim, J.-O. \& Mueller, C. W. Factor analysis: statistical methods and practical issues. Thousand Oaks, CA: Sage Publications. Quantitative Applications in the Social Sciences Series, No. 14, 1978 b.

17. Kerlinger, F. (1973). Foundations of behavioral research. New York: Holt, Rinehart, and Winston.

18. Kerlinger, F. N. (1978). Foundations of behavioral research. New York: McGraw-Hill.

19. Kim, S., Shin, D., Kalinowski, J., \& Park, K. (2005). The assessment of user satisfaction for a college laptop initiative using a quasi-Delphi method. The International Academy of Business and Economics - Proceedings, $1(1), 142-148$.

20. Kontos, G. (2004). The Laptop University: A faculty perspective. Educational Technology Review, 1, 1-11.

21. Locke, E. A. (1976). The nature and causes of job satisfaction. In_M. D. Dunnette (ed), Handbook of industrial and organizational psychology (pp. 1297-1349). New York: Holt Reinhart \& Winston.

22. Mahmood, M. A., Burn, J. M., Leopoldo, A. G., \& Jacquez, C. (2000). Variables affecting information technology end-user satisfaction a meta-analysis of the empirical literature. International Journal of Human-Computer Studies, 52, 751-771.

23. Marsh, H. W., \& Hocevar, D. Application of confirmatory factory analysis to the study of self-concept: First-and-higher-order factor models and their invariance across groups. Psychological Bulletin, 97, 562-582.

24. McVay, G. J., Snyder, K. D., \& Graetz, K. A. (2005). Evolution of a Laptop University: A case study. British Journal of Educational Technology, 36(3), 513-524.

25. Meade, A. W., Watson, A. M., \& Kroustalis, C. M. (2007, April). Assessing common methods bias in organizational research. Paper presented at the 22nd Annual Meeting of the Society for Industrial and Organizational Psychology, New York.

26. Oliver, R. L. (1980). A cognitive model for the antecedents and consequences of satisfaction. Journal of Marketing Research, 17, 460-469.

27. Oliver, R. L. (1993). Cognitive, affective, and attribute bases of the satisfaction response. Journal of Consumer Research, 20, 418-430.

28. Parasuraman, A., Zeithami, V. A., \& Berry, L. L. (1988). SERVQUAL: A multiple-item scale for measuring consumer perceptions of service quality. Journal of Retailing, 64(1), 12-40.

29. Poindexter, S., Basu, C., \& Kurncz, S. (2001). Technology, teamwork, and teaching: Meet in the classroom. Educause Quarterly, November, 32-41.

30. Rainer, K., \& Harrison, A. (1994). Toward development of the end user computing construct in a university setting. Decision Sciences, 24(6), 1187-1202.

31. Sanford, S. (2000). The E-Volution of Thinkpad. Converge, December, 67-70.

32. Schoenfeldt, L. F. (1984). Psychometric properties of organizational research instruments. In T. S. Bateman \& G. R. Ferris (eds), Methods and analysis in organizational research (pp. 68-80). Reston, VA: Reston Publishing Co.

33. Schreiber, J. B., Nora, A., Stage, F. K., Barlow, E. A., \& King, J. (2006). Reporting structural equation modeling and confirmatory factor analysis results: A review. The Journal of Educational Research, 99(6), 323-337.

34. Somers, T., Nelson, K., \& Karimi, J. (2003). Confirmatory factor analysis of the end-user computing satisfaction instrument: Replication within an ERP domain. Decision Sciences, 34(3), 595-622.

35. Schumacker, E. S., \& Lomax, R. G. (2010). Structural equation modeling. New York: Routledge, Taylor \& Francis Group.

36. Szajna, B., \& Scamell, R. W. (1999). The effects of information system user expectations on their performance and perceptions. MIS Quarterly, 17, 493-516.

37. The Learning Technology Report: The Laptop College (1999). Retrieved from http://www.theNode.org

38. Vroom, V. H. (1964). Work and motivation. New York: Wiley.

39. Yi, Y. (1990). A critical review of consumer satisfaction. In V. A. Zeithmal (ed.), Review of marketing_(4, pp. 68-123). Chicago: American Marketing Association, Chicago. 


\title{
APPENDIX 1
}

\section{LAPTOP INITIATIVE STUDENT SATISFACTION MEASURE}

\author{
A. Training and Orientation Support Provided to Adopters
}

1 = Strongly Disagree 2 = Disagree 3 = Neutral 4 = Agree 5 = Strongly Agree

\section{I am SATISFIED with the degree that.....}

A1. IT services provides sufficient training to faculty on how to use the laptop.

A2. IT services provides sufficient training to faculty on how to use the applications/software.

A3. IT services provide sufficient training to students on how to use the laptop.

A4. IT services provide sufficient training to students on how to use the applications/software.

A5. Laptops are issued to student users early in the first week of classes.

A6. The orientation pickup is made easy.

A7. In early orientation sessions students are shown how to take care of the laptop.

A8. The student orientation provides what support services are available, when they are accessible, and how to use these services.

*A9. (T1)There are frequent training classes provided for students.

*A10. (T2) There is a variety of methods to notify students of available training.

A11. Extensive time for orientation covering setup of wireless/use of machine/software/ and printer setup is provided.

A12. Both Faculty and Students have the same training.

A13. More seminars on training are provided at frequent time intervals and over a longer period of time.

\section{B. End User Support}

B1. Tutorials on the setup for printing documents in Morris Hall are provided.

*B2. (TS3) There is a Help Desk/Service Station located close to classrooms.

B3. Tutors are made available on campus during the first two weeks after orientation on "how to use laptops."

*B4. (TS2) IT services provide a prompt response to students who have Questions/Problems.

B5. There is Online Tutorials for how to use the laptop along with Frequently Asked Questions.

*B6. (FS1) The laptop is preset to work with MSU wireless.

B7. There is a specific hotline provided to College of Business student users for Questions/Help. (Help Line)

B8. Access to a Help Desk is available for extended hours (i.e. 6:00am - 11:00pm.)

B9. The MSU campus has strong wireless reception.

B10. If the computer breaks down there will be compatible software in computer labs on campus?

B11. Laptop problems are responded to in a rapid manner.

B12. There is a process in place to consistently maintain printers (i.e. ink, paper, breakdowns).

B13. Students are provided a process for Customer Complaints on how they are served by the Help Desk and service for machine malfunctions.

B14. Support for software questions (not tutoring but how to perform functions) as well as communication about where to go for questions is available.

\section{Technology}

C1. Users have upgrades for applications as well as references/help for applications provided with the computer.

C2. Technical support is readily available if there are problems with the laptop.

*C3. (FS2) Students are provided more access points to internet/and wireless.

*C4. (FS3) Electric power sources and work stations are widely available on campus. 
C5. There is a match between software used on laptops (in class/homework) and software used in the business world.

C6. Specific software for specific classes is used.

\section{Economic Issues}

D1. The cost of the laptop initiative is adequately explained.

D2. The $\$ 125$ user fee is adequately explained.

D3. Students are provided the opportunity to upgrade the laptop.

D4. Students have the choice of either leasing or buying.

D5. Students have the choice of what type of machine they want to purchase/lease.

*D6. (C1) Students are provided the opportunity to have input on the specifications of the computer.

\section{E. Enhancement of Learning/Use of Laptops in Classrooms}

E1. The expectations of students' laptop skills are clearly defined.

*E2. (RU1) The courses that state they are going to use the laptop actually use them.

*E3. (RU3) The laptop is used in a manner that supports communication between the teacher and student.

E4. All courses in the College of Business use the laptop.

E5. Teachers not read from Power Point presentations but teach.

E6. Assignments are disseminated on the web.

E7. The laptop initiative prepares me in the use of state of the art software.

*E8. (RU4) Courses are designed for the effective use of the laptop.

E9. Hands on experience with the laptop is provided in class on course related content.

E10. Adequate examples using technology be given by professors before projects are assigned.

E11. A clear definition of the goals for the laptop initiative is explained.

E12. The effective use of Laptops is determined from a student's perspective.

*E13. (C2) Students are allowed to use other types of laptops with compatible software.

E14. Classes define and highlight the importance of technology in today's work force.

E15. Professional behavior is required for usage of laptops in classrooms (i.e. not for e-mail, other personal distractions)

*E16. (RU2) The classroom use of laptops be clearly connected to the enhancement of student learning.

* = Identified items from Factor Analysis $(\mathrm{RU}=$ Relevant Use, $\mathrm{T}=$ Training, $\mathrm{TS}=$ Technical Support, FS = Facility Support, $\mathrm{C}=$ Choice)

\section{F. Students Overall Satisfaction with the Laptop Initiative}

1. My Overall Satisfaction with the MSU-Mankato College of Business Laptop Initiative is:

$$
\text { Very Dissatisfied Moderately Dissatisfied Neutral Moderately Satisfied Very Satisfied }
$$

2. I would recommend the College of Business laptop initiative to other students.

$$
\text { Strongly Disagree Moderately Disagree Neutral Moderately Agree Strongly Agree }
$$




\section{APPENDIX 2}

Item Correlation Matrix ( $\mathbf{N}=\mathbf{1 1 8})$

\begin{tabular}{|c|c|c|c|c|c|c|c|c|c|c|c|c|c|c|}
\hline & RU & RU & RU & RU & $\mathrm{T} 1$ & $\mathrm{~T} 2$ & TS1 & TS2 & TS3 & FS1 & FS2 & FS3 & $\mathrm{C} 1$ & $\mathrm{C} 2$ \\
\hline $\mathrm{RU}$ & 1 & & & & & & & & & & & & & \\
\hline $\mathrm{RU}$ & .437 & 1 & & & & & & & & & & & & \\
\hline $\mathrm{RU}$ & .544 & .516 & 1 & & & & & & & & & & & \\
\hline $\mathrm{RU}$ & .491 & .566 & .483 & 1 & & & & & & & & & & \\
\hline $\mathrm{T} 1$ & .258 & .264 & .262 & .336 & 1 & & & & & & & & & \\
\hline $\mathrm{T} 2$ & .131 & .241 & .181 & .188 & .569 & 1 & & & & & & & & \\
\hline TS1 & .362 & .268 & .323 & .270 & .291 & .246 & 1 & & & & & & & \\
\hline TS2 & .148 & .145 & .105 & .202 & .293 & .226 & .544 & 1 & & & & & & \\
\hline TS3 & .303 & .283 & .359 & .3 .72 & .282 & .177 & .503 & .391 & 1 & & & & & \\
\hline FS1 & .178 & .098 & .175 & .169 & .164 & .101 & .244 & .256 & .266 & 1 & & & & \\
\hline FS2 & .156 & .270 & .230 & .304 & .170 & .096 & .265 & .186 & .266 & .418 & 1 & & & \\
\hline FS3 & .315 & .167 & .430 & .187 & .293 & .158 & .303 & .062 & .332 & .440 & .330 & 1 & & \\
\hline $\mathrm{C} 1$ & .399 & .400 & .334 & .320 & .437 & .341 & .261 & .259 & .396 & .185 & .108 & .379 & 1 & \\
\hline $\mathrm{C} 2$ & .289 & .453 & .273 & .313 & .273 & .158 & .144 & .249 & .277 & .164 & .208 & .234 & .533 & 1 \\
\hline
\end{tabular}




\section{NOTES}

